\title{
Atividade crepuscular de Chlorotabanus inanis (Fab.) e Cryptotylus unicolor (Wied.) \\ (Diptera : Tabanidae)
}

\author{
J. A. Rafael \\ Instituto Nacional de Pesquisos \\ de Amoxōnio \\ J. D. Charlwood \\ Institute of Medical Research, \\ Papuc, New Guineo
}

\section{INTRODUÇÃo}

As mutucas do gênero Chlorotabanus Lutz e Cryptotylus Lutz formam um nítido grupo dentro da família Tabanidae pois as espécies desses gêneros parece serem todas crepusculares ou noturnas e, às vezes, quando suficientemente abundantes, sāo sérias pragas aos animais (Fairchild, 1940).

A distribuição de $C h$. inanis vai desde $O$ Brasil (Mato Grosso) até o México e $\mathrm{Cr}$. unicolor também desde o Mato Grosso até o Panamá (Fairchild, 1971). Não obstante a ampla distribuição na região neotropical, estas espécies não são comumente observadas, apesar de não serem raras, dado o fato de apresentarem hábitos crepusculares.
Baseados na ocorrência destas espécies, em relativa abundância na área de Manaus, passamos a fazer um estudo do ciclo diário da atividade de vôo das mesmas.

\section{MATERIAIS E MÉTODOS}

As capturas foram realizadas no Campus Universitário da Fundaçăo Universidade do Amazonas, localizado na periferia de Manaus $\left(03^{\circ} 08^{\prime} \mathrm{S}\right.$. e $60^{\circ} 00^{\prime} \mathrm{W}$.). Como atração para as mutucas, foi utilizado um cavalo adulto. As coletas, feitas com rede entomológica, foram realizadas, a princípio, desde as 05:00 até as 19:00 horas e, posteriormente, somente das 05:00 às 06:00 e 17:30 às 18:30 horas, capturando todas mutucas que chegassem para 
obter sangue no animal. Várias coletas foram realizadas nos meses de Agosto, Setembro e Outubro de 1978 e 1979.

Os dados de luminosidade foram tomados com um luximetro Metrawatt de quatro escalas, dando valores de menos de 1 até $500 \mathrm{mil}$ lux. Os dados de temperatura e umidade relativa foram obtidos junto ao serviço de meteorologia do INPA, situado próximo ao local de coleta.

\section{RES TADOS E DISCUSSÃO}

Dois distintos intervalos de atividade, um de manhã e outro à tarde, foram observados tanto para $\mathrm{Ch}$. inanis quanto para $\mathrm{Cr}$. unicolor. Ambas as espécies apresentaram atividades de vôos simultâneas, de manhă entre 05:20 e 05:50 e a tarde entre 17:45 e 18:20 horas, coincidindo, ambos os intervalos, com o nascer e o pôr do sol.

Os valores dos dados meteorológicos matutinos e vespertinos são mostrados na Tab. I, onde podemos notar que não houve coincidência para umidade relativa nem temperatura nos dois períodos diários de atividades. Os valores de luminosidade coincidiram para estes períodos e assim ficamos inclinados a aceitar que a intensidade de luz é a que mais

TABELA 1 - Dados de umidade relativa, temperatura e luminosidade durante a atividade de vôo de $\mathrm{Ch}$. inanis ( $\mathrm{Fab}$.) e $\mathrm{Cr}$. unicolor (Wied.) no Campus Universitário, Manaus, nos meses de Agosto, Setembro e Outubro de 1978 e 1979

\begin{tabular}{l|cc}
\hline & $\begin{array}{c}\text { Manhä } \\
(05: 20-05: 50)\end{array}$ & $\begin{array}{c}\text { Tarde } \\
(17: 45-18: 20)\end{array}$ \\
\hline Temperatura $\left({ }^{\circ} \mathrm{C}\right)$ & $23,2 \pm 1,0$ & $27,0 \pm 1,6$ \\
\hline Umidade relativa $(\%)$ & $95,3 \pm 2,0$ & $81,3 \pm 10,1$ \\
\hline Luminosidade (lux) & 2,0 a 1.500 & 1.400 a 1,0 \\
\hline
\end{tabular}

influencia na atividade de vôo de $C h$. inanis e $\mathrm{Cr}$. unicolor, estando estas espécies adap. tadas para o vôo no periodo crepuscular e nāo apresentando atividade durante a maior parte do dia, em face da alta luminosidade. Estes resultados estāo de conformidade com as observaçōes de Philip \& Fairchild (1956), em que estas espécies apresentam hábitos crepusculares.

Mesmo não havendo coincidência entre temperatura e umidade relativa nos dois períodos, os valores estão próximos e podem estar dentro de um índice ótimo para a atividade destas espécies.

A relevância em conhecer-se o ciclo diário de atividade de Tabanidae, bem como de outras espécies de dípteros hematófagos de importância médica ou veterinária, está relacionada à importância epidemiológica da população. Há evidências quanto aos tabanídeos africanos de que as fêmeas jovens (nuliparas) tendem a voar de manhã, enquanto as mais velhas (oníparas) tendem a voar à tarde (Duke, 1959), sendo estas últimas epidemiologicamente mais importantes, pois já obtiveram um ou mais repastos sangüineos e, portanto, atuam mais facilmente na transmissão de agentes patogênicos.

\section{AgRADECIMENTOS}

Os autores agradecem ao Dr. G.B. Fairchild, Universidade da Flórida, EUA, pela identificação dos tabanídeos e à Fundação Universidade do Amazonas pelo empréstimo do animal que foi utilizado como isca.

\section{SUMMARY}

Utilizing an adult horse for attraction of horse flies, Chlorotabanus inanis (Fab.) and Cryptotylus unicolor (Wied.) demonstrate flight activity for feeding only below 1,500 lux. During the day they present biphasic activity: one in the morning between 5:20 and 5:50 a.m. and the other in the ofternoon between $5: 45$ and $6: 20$ p.m., coinciding with both the rising and setting of the sun. 


\section{REFERENCIAS BIBLIOGRAFICAS}

DUKE, B.O.L.

1960 - Studies on the biting habits of Chrysops VIII. The biting cycles of nulliparous and parous C. silacea and C. dimidiata (Bomb form). Ann. Trop. Med. Parasitol., 54 (2): 147-155.

FAIRCHILD, G.B.

1940 - Notes on Tabanidae (Diptera) from Panama 1. The genera Chlorotabanus and Cryptoty. lus. Rev. Ent., 11: 714-722.
1971 - A catalogue of the Diptera of the Americas South of the United States. 28. Family Tabanidae. Museu de Zoologia, Univ. Sảo Pau10, $163 \mathrm{pp}$.

PHILIP, C.B. \& FAIRCHILD, G.B.

1956 - American biting flies of the genera Chlorotabanus Lutz and Cryptotylus Lutz (Diptera: Tabanidae). Ann. Ent. Soc. Am., 49 (4): 313-324.

(Aceito para publicação em $02 / 12 / 80$ ) 